\title{
Crucial differences between undergraduate biochemical education in Brazil and developed countries: history and perspectives
}

\author{
Bracht, A
}

\section{Departamento de Bioquímica, Universidade Estadual de Maringá, Maringá, Brazil}

The crucial difference between the biochemical education in Brazil and more developed countries resides not in the highest degrees but in the lowest ones: the bachelor degree in Biochemistry is still a rarity in Brazil. Whereas more than 600 institutions in the US offer the bachelor degree in biochemistry/molecular biology, presently only 3 are offered in Brazil. This situation may be surprising, but it has historical reasons among others. The field of Biochemistry in Brazil played a pioneering role in institutionalizing master's and doctoral programs, thus reinforcing also research activities. Teachers and researchers involved in these programs, however, had in general little if any interest in implementing undergraduate biochemistry studies, except as a fundamental one year discipline to be taken by future biologists, pharmacists, medical students, etc. The second reason for the virtual absence of the biochemistry bachelor degree before 2005 in Brazil are the so called baccalaureates in "Pharmacy and Biochemistry" a strange denomination whose more correct name should be "Pharmacy and Clinical Analyses". This situation generated the notion, within and outside academic circles, that there is a very especial relationship between Pharmacy and Biochemistry or even that they are one and the same thing. These and other erroneous notions have proven to be adverse for the brazilian biochemistry in both professional and academic spheres, especially in more recent times when the master's and doctoral programs ceased to offer the more basic disciplines. Many graduates with a master's or even doctoral degree have a highly defficient background on physical and organic chemistry, or even on metabolic biochemistry and enzymology if the program is centered on molecular biology.

Word Keys: biochemistry, undergraduate education, bachelor degree. 